\title{
Effect of non-steroidal anti-inflammatory drugs on colon carcinoma Caco-2 cell responsiveness to topoisomerase inhibitor drugs
}

\author{
P Ricchi',2, T Di Matola', G Ruggiero', D Zanzi', A Apicella', A di Palma', M Pensabene', S Pignata', R Zarrilli' \\ and AM Acquaviva*,I
}

'Dipartimento di Biologia e Patologia Cellulare e Molecolare 'L. Califano', Istituto di Endocrinologia ed Oncologia Sperimentale 'G. Salvatore' del Consiglio Nazionale delle Ricerche, Università 'Federico II', Napoli, 80131 Italy; '2Divisione di Oncologia Medica B, Istituto Nazionale Tumori, Fondazione G. Pascale, Napoli, Italy

\begin{abstract}
Numerous studies demonstrate that the chemopreventive effect of non-steroidal anti-inflammatory drugs on colon cancer is mediated through inhibition of cell growth and induction of apoptosis. For these effects non-steroidal anti-inflammatory drugs have been recently employed as sensitising agents in chemotherapy. We have shown previously that treatments with aspirin and NS-398, a cyclo-oxygenase-2 selective inhibitor, affect proliferation, differentiation and apoptosis of the human colon adenocarcinoma Caco-2 cells. In the present study, we have evaluated the effects of aspirin and NS-398 non-steroidal antiinflammatory drugs on sensitivity of Caco-2 cells to irinotecan (CPT II) and etoposide (Vp-I6) topoisomerase poisons. We find that aspirin co-treatment is able to prevent anticancer drug-induced toxicity, whereas NS-398 co-treatment poorly affects anticancer drug-induced apoptosis. These effects correlate with the different ability of aspirin and NS-398 to interfere with cell cycle during anticancer drug co-treatment. Furthermore, aspirin treatment is associated with an increase in bcl-2 expression, which persists in the presence of the anticancer drugs. Our data indicate that aspirin, but not NS-398, determines a cell cycle arrest associated with death suppression. This provides a plausible mechanism for the inhibition of apoptosis and increase in survival observed in anticancer drug and aspirin co-treatment.

British Journal of Cancer (2002) 86, I50I- I509. DOI: 10.1038/sj/bjc/6600289 www.bjcancer.com

(c) 2002 Cancer Research UK
\end{abstract}

Keywords: aspirin; NS-398; cell cycle; Bcl-2; colon cancer; topoisomerase inhibitors

Numerous studies have shown that the chemopreventive effect of Non-Steroidal Anti-inflammatory drugs (NSAIDs) on colon cancer is mediated through inhibition of cell growth and induction of apoptosis (Lu et al, 1995; Piazza et al, 1995; Shiff et al, 1995; Arber et al, 1997). In particular, several investigators have found that aspirin and other NSAID treatments correlate with a decrease in cell replication and with an increased proportion of cells arrested at the G0/G1 phase of the cell cycle (Piazza et al, 1995; Shiff et al, 1995, 1996; Arber et al, 1997). The molecular mechanisms responsible for the effect of NSAIDs on cell growth and apoptosis are controversial, being either related to their ability to inhibit cyclooxygenase activity and prostaglandin synthesis or independent from a prostaglandin pathway (Chan et al, 1998; Sheng et al, 1998; Smith et al, 2000).

More recently, several reports demonstrated that combinations of different agents for cancer prevention is more effective than using either a single agent alone (Li et al, 1999; Torrance et al, 2000). Combination therapy is a strategy currently used to treat

\footnotetext{
* Correspondence: Professor AM Acquaviva; Dipartimento di Biologia e Patologia Cellulare e Molecolare, Facoltà di Medicina e Chirurgia, Università 'Federico II', via S. Pansini 5, 80। 3 I Napoli, Italy;

E-mail: angacqua@unina.it.

Received II October 200I; revised 27 February 2002; accepted 3 March 2002
}

cancer and NSAIDs, for their effects on cell growth and apoptosis, are potential chemotherapeutic agents to be used alone or in combination with conventional anticancer drugs. Only a few studies have accurately evaluated this possibility (Lundholm et al, 1994; Sinicrope et al, 1996; Duffy et al, 1998) and more recently cyclooxygenase-2 (Cox-2) selective inhibitors have been found to enhance the sensitivity to anticancer drugs (Soriano et al, 1999; Hida et al, 2000). Thus, the need for an accurate evaluation of all the potential interactions between these two classes of drugs.

In a previous work we have shown that aspirin treatment may affect the proliferation, differentiation and apoptosis of the human colon adenocarcinoma Caco-2 cells; in particular, we observed that, depending on the doses, aspirin treatment may induce apoptosis and a significant DNA synthesis inhibition associated with a modification in the level of the insulin-like growth factor II (IGF-II) (Ricchi et al, 1997), an autocrine growth factor for this cell line (Zarrilli et al, 1994, 1996). More recently, we have demonstrated that NS-398, a Cox-2 selective inhibitor, also affects Caco-2 DNA synthesis and apoptosis (Di Popolo et al, 2000).

Accumulating evidence suggest that interference with cell cycle and/or with the intracellular growth factor (receptor)-activated signal transduction pathways are key modulators of cellular response to chemotherapeutic agents (Donaldson et al, 1994; Ciardiello et al, 1996; Tortora et al, 1997; Chen et al, 1997; De Luca et al, 1997; Lin et al, 1998). Because aspirin and NS-398 are able to inhibit cell growth, we asked whether they might modify sensitivity 
to anticancer drugs. Because cell killing induced by the topoisomerase poisons irinotecan (CPT 11) and etoposide (VP-16) is strictly cell cycle dependent (Nitiss and Beck, 1996; Goldwasser et al, 1995) and ultimately activates a pathway of programmed cell death, we have decided to use these anticancer drugs to evaluate our hypothesis. Irinotecan (CPT 11) was selected also because it is one of the most active anticancer agent in colon cancer (Rougier et al, 1998). We have additionally evaluated whether the effect of aspirin and NS-398 treatments on the sensitivity of Caco- 2 cells to anticancer drugs correlate with any modification in the level of the bcl-2 family protein, one of the key regulator factors in apoptosis (Yang et al, 1995; Korsmeyer 1999).

Here we find that, depending on the concentration, NS-398 treatment poorly affects Caco-2 anticancer sensitivity, while aspirin treatment, counteracting anticancer drug-induced cell cycle modification and inducing the expression of bcl-2, is able to substantially alter Caco-2 anticancer drug-induced apoptosis and overall viability.

\section{MATERIALS AND METHODS}

\section{Cell growth and culture}

Caco-2 cells were routinely grown in $100 \mathrm{~mm}$ plastic dishes at $37^{\circ} \mathrm{C}$ in a humidified incubator $5 \% \mathrm{CO}_{2}-95 \%$ air atmosphere in Dulbecco's Modified Eagle's Medium (DMEM) supplemented with $10 \%$ foetal calf serum, glutamine $(2 \mathrm{mM})$, penicillin $\left(100 \mathrm{u} \mathrm{ml}^{-1}\right)$, and streptomycin $\left(100 \mu \mathrm{g} \mathrm{ml}^{-1}\right)$ and buffered with N-2-hydroxyethylpiperazine- $\mathrm{N}^{\prime}$-2-ethane sulphonic acid (HEPES) (20 mM). Caco-2 cells were seeded at $5 \times 10^{4}$ cells $\mathrm{ml}^{-1}$ and were routinely sub-cultured when about $80 \%$ confluent. The culture medium was changed every other day. Confluence was reached 6-8 days after the inoculum and the stationary phase on day 10 . Cell cultures were stopped after 15 passages.

Etoposide and irinotecan were a gift from Bristol-MyersSquibb (Rome, Italy) and Rhone Poulen, respectively; anticancer drugs were diluted in DMEM to prepare $500 \times$ concentrated solutions. Aspirin (Sigma, Milan, Italy) was dissolved in a $0.1 \mathrm{M}$ Tris- $\mathrm{HCl} \mathrm{pH} 7.8$ solution. The solutions were buffered with Tris base to obtain the final $\mathrm{pH}$ equal to that of control DMEM medium and prepared every two weeks. Experiments were performed in the absence or in the presence of aspirin. In aspirin untreated cells (control) anticancer drugs were added for $48 \mathrm{~h}$ at day 4 of culture. In treated cells aspirin was added at day 3 of culture for $24 \mathrm{~h}$. Anticancer drugs were added for $48 \mathrm{~h}$ in presence of aspirin or NS 398 (co-treatment) without changing media.

\section{Cell cycle analysis and apoptosis detection}

In order to define the cell cycle distribution and apoptosis rate, Caco-2 cells were trypsinised, pelletted, fixed and Propidium Iodide (PI) stained as previously described (Nicoletti et al, 1991). PI staining fluorescence of individual cells was analysed by using a FACS Calibur flow cytometer apparatus (Becton \& Dickinson, Mountain View, CA, USA) and the MODFIT analysis software. For each sample, at least 20000 events were stored.

Apoptosis/necrosis ratio was additionally evaluated by using annexin V-FITC/PI double staining technique. Briefly, trypsinized Caco-2 cells were collected, including floating apoptotic cells and the cells spontaneously detached during washing procedure, and annexin V-FITC and PI co-stained by using a detection kit from Medical \& Biological Laboratories Co, Ltd, Naka-ku Nagoya Japan, according to the manufacturer's instructions. Fluorescence analysis was performed by a flow cytometer apparatus (Becton \& Dickinson, Mountain View, CA, USA) and the Cell Quest analysis software. For each sample, at least 30000 events were stored. Quadrant settings were based on the negative control. Each experiment was repeated at least three times.

\section{Plating efficiency assay}

To determine anticancer drug responsiveness of Caco-2 cells a plating efficiency assay was performed following drug removal. After each treatment, cells were trypsinised, washed and seeded $(15000$ cells $\times$ well $)$ in triplicate in 24 multiwell cluster dishes and counted at days $1,4,6,8$ and 11 of culture.

\section{Western blot analysis}

Mouse monoclonal antibody to Bcl-2 was from Santa Cruz Biotechnology, Santa Cruz CA, USA. Cells were washed in cold PBS and lysed for $10 \mathrm{~min}$ at $4{ }^{\circ} \mathrm{C}$ with $1 \mathrm{ml}$ of lysis buffer ( $50 \mathrm{~mm}$ Tris, $\mathrm{pH} 7.4, \quad 0.5 \% \quad \mathrm{NP} 40, \quad 0.01 \%$ SDS) containing protease inhibitors. Lysates from adherent cells collected by scraping were centrifuged at $12000 \mathrm{~g}$ for $15 \mathrm{~min}$ at $4^{\circ} \mathrm{C}$. The protein concentration in cell lysates was determined by BioRad Protein Assay (Bio-Rad, Richmond CA, USA) and $50 \mu \mathrm{g}$ of total protein from each sample was analysed. Proteins were separated by a $12 \%$ SDS-polyacrylamide gel electrophoresis and transferred on nitro-cellulose membrane (Hybond-ECL Nitrocellulose, Amsherman, Rainham, UK). Membranes were blocked in 5\% non-fat dry milk, and after three washes, were incubated for $1 \mathrm{~h}$ at $4{ }^{\circ} \mathrm{C}$ with $0.5 \mu \mathrm{g} \mathrm{ml}^{-1}$ of mouse monoclonal primary antibody in PBS. After five washes, filters were incubated for $1 \mathrm{~h}$ at $4^{\circ} \mathrm{C}$ with horseradish peroxidase-conjugated anti-mouse secondary antibodies (Bio Rad) diluted 1:2000 in PBS, $0.2 \%$ Tween. The membranes were then washed and protein bands were detected by an enhanced chemiluminescence system (Amersham Pharmacia Biotech). Control for loading and transfer was obtained by probing with anti- $\alpha$-tubulin (Sigma) at $1: 4000$ dilution. For quantitation of immunoblots, relative intensities of bands were quantified by densitometry with a desk scanner (Pharmacia Discovery system) and RFLPrint software (PDI, New York, USA)

\section{Statistical analysis}

Statistical comparisons were performed using the Mann-Whitney $U$-test. A probability value $P<0.05$ was considered a significant difference.

\section{RESULTS}

\section{Effect of aspirin treatment on proliferation and apoptosis} of Caco-2 cells

Our previous data indicated that a $24 \mathrm{~h}$ aspirin treatment on Caco2 cells at doses ranging from 1 to $10 \mathrm{~mm}$ determined a dose-dependent inhibition of DNA synthesis and a significant increase in levels of apoptosis (Ricchi et al, 1997). In the present work, we confirmed these results on cell growth for a $72 \mathrm{~h}$ treatment (data not shown) and evaluated again the effects on apoptosis by analysing the percentage of sub-G1 population at flow cytometry. Treatment with aspirin for $72 \mathrm{~h}$, caused a dose-dependent increase in apoptosis starting from the concentration of $5 \mathrm{~mm}$ aspirin; the percentage of apoptotic cells was approximately $6 \%$ in control cells and 5, 9 and $12 \%$ in cells treated with aspirin at 2, 5 and $10 \mathrm{mM}$, respectively (data not shown).

The above data suggest that aspirin acts in Caco-2 cells as anticancer agent with cytostatic properties and ability to induce apoptosis at high dosages. Therefore we decided to select these antiproliferative, apoptotic dosages of drugs to study whether they could modify Caco-2 sensitivity to anticancer drug treatments. 


\section{Effect of aspirin co-treatment on CPT 11 and Vp-16-induced apoptosis}

To determine the effect of anticancer drugs on apoptosis, Caco-2 cells were exposed for $48 \mathrm{~h}$ at different concentrations of VP-16 and CPT 11 and DNA ploidy was analysed by flow cytometry. The effects on apoptosis in Caco-2 cells are shown in Figure 1. Both Vp-16 and CPT 11 dose-dependently increased the levels of apoptosis in Caco-2 cells: Vp-16 increased apoptosis from $8 \%$ at $4.25 \mu \mathrm{M}$ to $20 \%$ at $34 \mu \mathrm{M}$ (Figure 1A) and CPT 11 increased apoptosis from $9 \%$ at $5 \mu \mathrm{M}$ to $16 \%$ at $15 \mu \mathrm{M}$ (Figure 1B). These data suggest that apoptosis may have a role in drug-induced Caco-2 cells cytotoxicity especially at high concentrations of the drugs.

To evaluate whether aspirin may affect cell killing by topoisomerase drugs, we tested a schedule of administration in which the effects of aspirin treatment on Caco-2 cell growth were present at moment of anticancer-drug exposure: cells were pre-treated with aspirin for $24 \mathrm{~h}$ and subsequently exposed for $48 \mathrm{~h}$ to the aforementioned ranges of drugs in the continuous presence of NSAIDs (co-treatment). We evaluated the interference of $2 \mathrm{mM}$ aspirin with anticancer drug induced apoptosis through the analysis of the sub-diploid DNA peak at flow cytometry. As shown in Figure 1, the levels of apoptosis were reduced for each concentration of both anticancer drugs when administered in the presence of aspirin compared with single agent treatment. Aspirin-co-treated Caco-2 cells were particularly resistant to etoposide-induced apoptosis: in fact the percentage of apoptosis in cells co-treated with
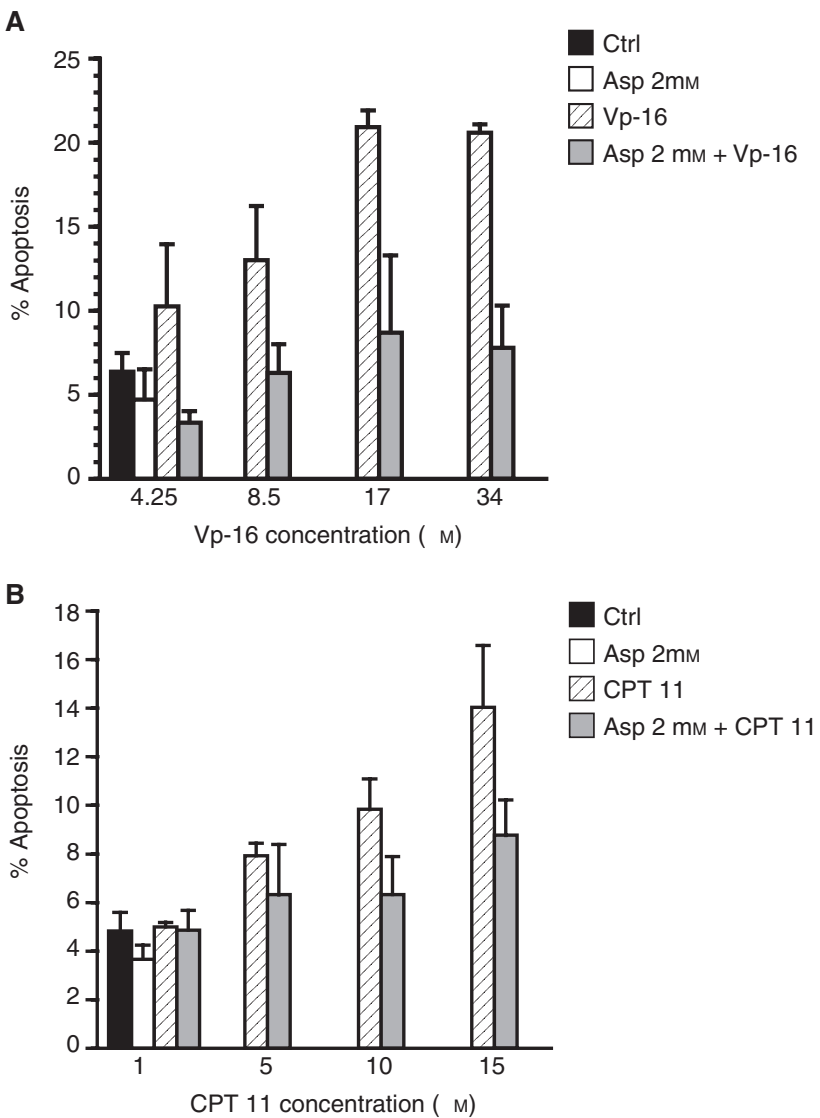

Figure I Effect of $2 \mathrm{mM}$ aspirin co-treatment on VP-16-(A) and CPT I I (B)-induced apoptosis in Caco-2 cells. Cells at day 3 were incubated with aspirin for $24 \mathrm{~h}$, then anticancer drugs at the indicated concentrations were added in presence of $2 \mathrm{mM}$ aspirin for $48 \mathrm{~h}$. Apoptosis was calculated as the percentage of cells showing a sub-diploid DNA peak as described in Materials and Methods. Data are expressed as mean \pm s.d. aspirin and $\mathrm{Vp}-16$ at 8.5 and $17 \mu \mathrm{M}$ decreased from 14 to $7 \%$ and from 21 to $9 \%$, respectively. The effect of aspirin on druginduced apoptosis was similar when aspirin and anticancer drugs were simultaneously administered (data not shown). These results indicate that aspirin-dependent inhibition of proliferation is associated with a reduced ability of the drug to induce apoptosis.

To quantify the effects of aspirin co-treatment on Vp-16induced apoptosis and to determine whether this effect was present at concentration in which aspirin was already apoptotic by itself, we used annexin V-FITC/propidium iodide staining assay. In fact this assay allows to clearly distinguish viable cells from those undergoing different stages of apoptosis or necrosis. The effect of aspirin at 2 and $5 \mathrm{~mm}$ concentration on $\mathrm{Vp}$-16-induced toxicity in Caco-2 cells is analysed in Figure 2. Dot plots of green (Annexin V-FITC) $v s$ red (PI) fluorescence showed four separate clusters: viable cell (lower left quadrant), cells at early stage of apoptosis, (upper left quadrant), cell at late stage of apoptosis (upper right quadrant), necrotic cells (lower right quadrant). Because of the high sensitiveness of this procedure, we detected higher levels of apoptosis as compared to that obtained at the analysis of subdiploid peak. Vp-16 at $17 \mu \mathrm{M}$ increased the percentage of early and late apoptotic cells from 13 to $48 \%$ and decreased the percentage of viable cell from 75 to $49 \%$ (Figure 2A,D). Aspirin cotreatment at 2 and $5 \mathrm{~mm}$ dose-dependently decreased the percentage of early and apoptotic cells from 48 to 36 and $18 \%$, respectively, (Figure 2D vs E,F) and increased the percentage of viable cells from 49 to 59 and $70 \%$ (Figure 2D vs E,F); similar data were obtained for $\mathrm{Vp}-16$ at $8.5 \mu \mathrm{M}$ (data not shown) and CPT 11 at $10 \mu \mathrm{M}$ (Figure 3 ). Not significant change in the levels of necrosis was observed.

We also evaluated whether the effects of aspirin co-treatment on anticancer drug responsiveness were unique of Caco-2 cells or were obtainable in other colon cancer cells showing different Cox isoform expression profile. We selected the colon cancer cell line SW480 being Cox-1 positive, but Cox- 2 negative (Smith et al, 2000). SW480 cells were co-treated with aspirin and topoisomerase inhibitors under the above mentioned experimental conditions. Aspirin co-treatment at 2 and $5 \mathrm{~mm}$ decreased both CPT 11and VP-16-induced apoptosis. The effect was dose-dependent and in the same range of magnitude of that obtained in Caco- 2 cells (data not shown).

\section{Effect of NS-398 co-treatment on Vp-16 and CPT-11-induced apoptosis in Caco-2 cells}

Data from our laboratory indicated that Caco-2 cells express Cox-2 but not Cox-1 and NS-398, a COX-2 selective inhibitor, inhibited DNA synthesis and induced apoptosis in Caco-2 cells (Di Popolo et $a l, 2000)$. To evaluate whether the effects of aspirin co-treatment on Caco- 2 cells were dependent on the inhibition of Cox- 2 activity, we analysed the effect of NS-398 co-treatment on anticancer druginduced apoptosis.

We firstly evaluated the effect on apoptosis of NS-398 $72 \mathrm{~h}$ treatment at different concentration using annexin V-FITC/propidium iodide staining assay. As shown in Figure 4, 10 and $50 \mu \mathrm{M}$ NS-398 treatment induced higher level of apoptosis compared with 2 and $5 \mathrm{~mm}$ aspirin treatments in Caco-2 cells $(22$ and $25 \%$ compared with 12 and $20 \%$, respectively).

Then we evaluated the effect of NS-398 co-treatment on Vp-16and CPT 11-induced toxicity. The percentage of cells in early plus late apoptosis $v s$ viable cells induced by co-treatments with aspirin or NS-398 and Vp-16 or CPT 11 are given in Figure 3.

Aspirin at 2 and $5 \mathrm{~mm}$ dose-dependently decreased both Vp16and CPT 11-induced apoptosis and increased cell viability. NS 398

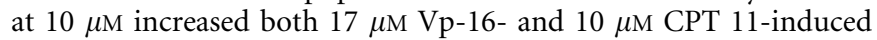
apoptosis $(P<0.05$ and $P>0.05$, respectively), while NS 398 at $50 \mu \mathrm{M}$ decreased $17 \mu \mathrm{M} \mathrm{Vp}-16$ - and $10 \mu \mathrm{M}$ CPT 11-dependent apoptosis $(P>0.05$ and $P<0.05$, respectively). NS 398 at $10 \mu \mathrm{M}$ 
A

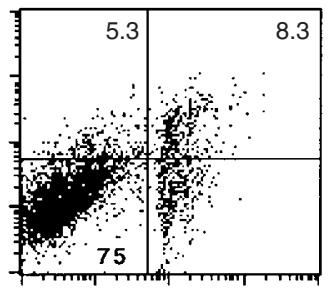

C

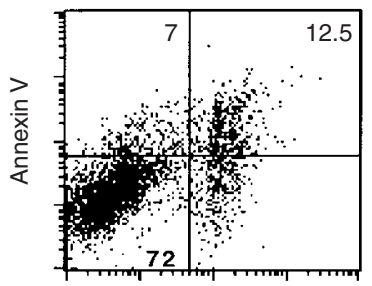

E

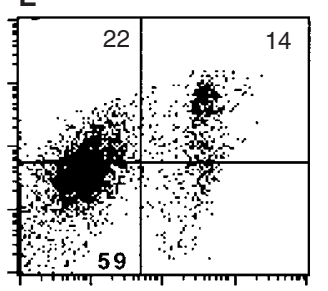

B

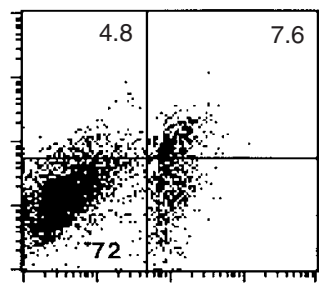

D

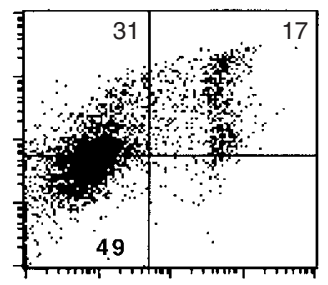

F

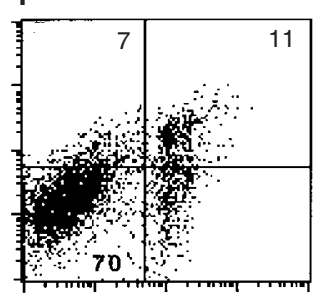

Propidium iodide

Figure 2 Effect of aspirin co-treatment on annexin V-FITC/PI staining of Caco-2 cells. Cells at day 3 were incubated with aspirin for $24 \mathrm{~h}$, then anticancer drugs were added in presence of aspirin for $48 \mathrm{~h}$. Four distinct phenotypes become distinguishable: (i) viable cells (lower left quadrant); (ii) cells at early stage of apoptosis (upper left quadrant); (iii) cells at late stage of apoptosis (upper right quadrant); (iiii) necrotic cells (lower right quadrant). (A) untreated cells; (B) cells treated with $2 \mathrm{mM}$ Aspirin; (C) cells treated with $5 \mathrm{mM}$ Aspirin; (D) cell treated with $17 \mu \mathrm{M} \vee \mathrm{p}$-16; (E) cells co-treated with $2 \mathrm{mM}$ aspirin and $17 \mu \mathrm{M} \mathrm{Vp}$-16; (F) cells co-treated with $5 \mathrm{~mm}$ aspirin and $17 \mu \mathrm{M} \vee \mathrm{p}-16$. Data represent one of three similar experiments.

did not significantly alter the percentage of viable cells following treatment with Vp-16- or CPT 11 co-treated cells, while NS 398 at $50 \mu \mathrm{M}$ increased cell viability of $\mathrm{Vp}$-16-treated cells from 40 to $52 \% \quad(P<0.05)$. No effects were obtained on anticancer drug induced-apoptosis with NS 398 at $1 \mu \mathrm{M}$ (data not shown).

\section{Effect of anticancer drug treatments and anticancer drug plus aspirin or NS-398 co-treatments on cell cycle distribution}

We examined whether aspirin and NS-398 treatments had any distinct effect on cell cycle parameter under the same experimental conditions. The distribution of cells in the phases of the cell cycle is presented in Table 1. Aspirin treatment was associated with a modest dose-dependent increase in the proportion of cells in the S phase, while NS-398 did not significantly alter cell cycle parameters with respect to control cells.

We also asked whether the different effect of aspirin and NS-398 on survival could be determined by a selective interference with anticancer drug-induced cell cycle arrest. In fact, Vp-16 arrests cells in the pre-mitotic phase of the cell cycle leading to accumulation of the cells in the late S or G2 phase (Fearnhead et al, 1994; Downes et al, 1994); while CPT 11 causes S phase slowing (Shao et al, 1997; McDonald and Brown, 1998). Effect of Vp-16 and CPT 11 treated, Vp-16 and CPT 11 plus aspirin or plus NS-398 co-treated cells

under previously described experimental conditions are shown in Table 2. We found that $\mathrm{Vp}-16$, from lowest concentration of drug tested, increased the distribution of Caco-2 cells at the G2 phase of the cell cycle. In particular, VP-16 at $8.5 \mu \mathrm{M}$ and $17 \mu \mathrm{M}$ treatments were able to trap 85 and $91 \%$ of Caco-2 cells in the G2 phase of cell cycle, respectively. Whereas CPT 11 at 10 and $15 \mu \mathrm{m}$ treatments accumulated 70 and $85 \%$ of Caco- 2 cells in the S phase of cell cycle, respectively (Table 2 and data not shown). Aspirin and NS-398 co-treatment had different effect on anticancer druginduced cell cycle distribution: in cells that have been co-treated with Vp-16 at $17 \mu \mathrm{M}$, aspirin dose-dependently increased the percentage of Caco-2 cells at G0-G1 phase of cell cycle. NS-398 at $10 \mu \mathrm{M}$ had no effect on Vp-16-induced accumulation at the G2 phase of cell cycle, while at $50 \mu \mathrm{m}$ increased the percentage of cells at $\mathrm{G} 0-\mathrm{G} 1$ phase from 9 to $15 \%$. In cells that have been co-treated with aspirin and CPT 11 at $10 \mu \mathrm{M}$ there was an increase in the percentage of cells at $\mathrm{G} 0-\mathrm{G} 1$ phase similar to that observed in Vp-16 co-treated cells. NS-398 only at $50 \mu \mathrm{M}$ concentration increased the percentage of cells at G0-G1 phase from 22 to $32 \%$ (Table 2).

\section{Effect of aspirin co-treatment on Caco-2 plating efficiency}

Several reports indicate that cancer cells after a genotoxic treatment can take hours to many days before dying (Vidair et al, 1996; Han et al, 1997). To better evaluate the cytoprotective effect of aspirin, also with respect to potential delayed toxicity of $\mathrm{Vp}-16$, we measured overall cell viability by performing a plating efficiency assay following $8.5 \mu \mathrm{M}$ and $17 \mu \mathrm{M}$ etoposide treatments and cotreatments with either 2 or $5 \mathrm{~mm}$ aspirin (Figure $5 \mathrm{~A}, \mathrm{~B}$ ). All replated control Caco-2 cells started to divide after a lag period of $48 \mathrm{~h}$ (Figure 5A); they entered into the exponential phase of cell growth at day 4 , and reached the stationary phase at day 14 (data not shown). Etoposide treatments at both concentrations produced an approximately 0.7 -fold decrease of the cell number at day 4 after replating; the fraction of surviving cells entered into the logarithmic phase of cell growth only at day 8 . On the contrary, aspirin co-treated cells more efficiently replated and started the exponential phase of cell growth at day $6,5 \mathrm{~mm}$ aspirin co-treated cells showing the best profile of cell growth. Thus, aspirin co-treated cells appeared to be more viable and less sensitive to anticancer delayed toxicity. Etoposide at $34 \mu \mathrm{M}$ was such a toxic treatment that cell restarted to divide only at day 11; nevertheless, cells cotreated with aspirin and etoposide also at this concentration, continued to show an advantage in cell growth (data not shown).

\section{Effect of different treatments on the expression of the bcl-2 protein family}

The proteins belonging to the $\mathrm{Bcl}-2$ family are important regulators of cell death in eukaryotes (Yang et al, 1995; Korsmeyer, 1999). The apoptotic response of a cell damage by chemotherapy may depend at least in part, on the balance between proteins which predispose against genotoxic to programmed cell death such as bad and bax and proteins which antagonise programmed cell death, such as bcl-2 and bclx-xl (Yang et al, 1995; Korsmeyer, 1999). To study the mechanisms that mediate the effect of aspirin and NS-398 on anticancer drugs Caco-2 cell sensitivity, we investigated whether these treatments were associated with a modulation of the expression of these proteins. Soluble cell lysates were obtained from control cells and from cell treated with aspirin at 2 and $5 \mathrm{~mm}$ and NS-398 at $10 \mu \mathrm{M}$ and $50 \mu \mathrm{M}$ doses for $72 \mathrm{~h}$. Expression of bad, bax and bclx-xl were not affected by any treatment (data not shown); in contrast, more extensive modifications were observed in the levels of bcl-2 (Figure 6A): aspirin at 2 and $5 \mathrm{~mm}$ increased bcl-2 levels dose-dependently by 1.5 - and two-fold, respectively, compared with untreated cells; on the contrary, NS398 at $10 \mu \mathrm{M}$ and $50 \mu \mathrm{M}$ decreased the levels of bcl-2 by three- 
Apoptotic cells $\square$ Viable cells

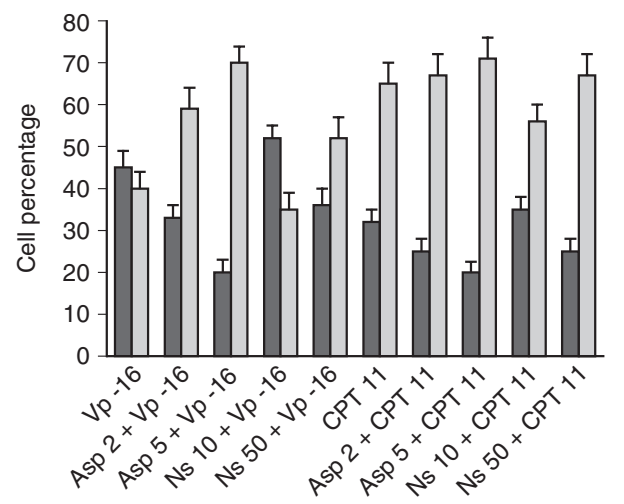

Figure 3 Effect of aspirin and NS-398 co-treatment on $17 \mu \mathrm{M} \mathrm{Vp-16-}$ and $10 \mu \mathrm{M}$ CPT II- induced apoptosis of Caco-2 cells. The percentage of viable and apoptotic cells were calculated as reported in Figure 2. Apoptotic bars are the sum of percentage of cells at early and late stages of apoptosis. Data are expressed as mean \pm s.d. Data points represent the mean of triplicate experiments.

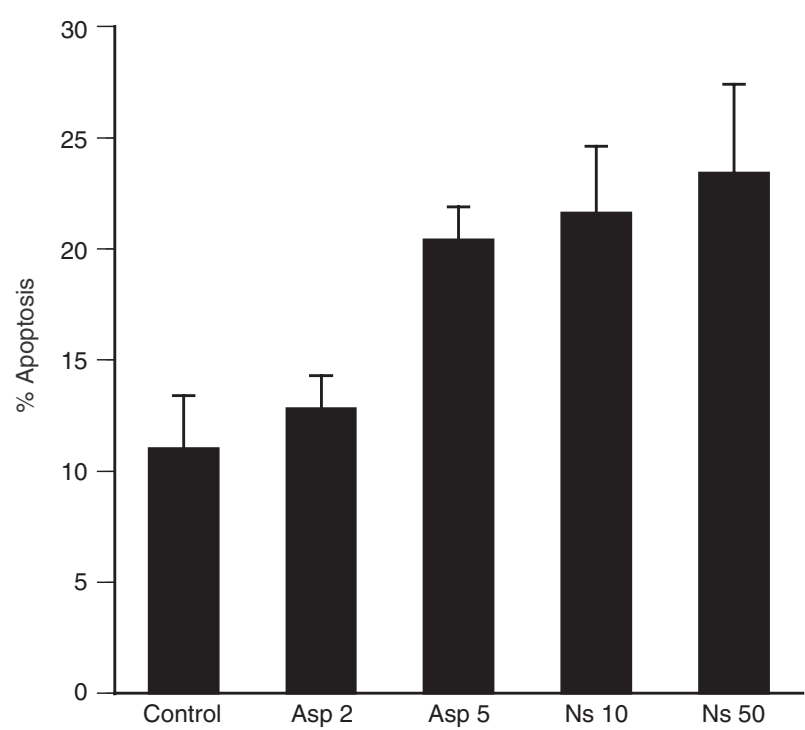

Figure 4 Effect of 2 and $5 \mathrm{mM}$ aspirin and 10 and $50 \mu \mathrm{M}$ NS-398 $72 \mathrm{~h}$ treatment on apoptosis of Caco-2 cells. The percentage of Caco-2 cells at early and late stages of apoptosis was quantified as reported in Figure 2. Data points represent the mean of triplicate experiments \pm s.d.

and two-fold, respectively. Thus, aspirin, but not NS-398, treatment increased the ratio bcl-2 to bax determining a pattern of survival in Caco-2 cells, which was most evident at $5 \mathrm{~mm}$ treatment. Then we asked whether etoposide treatment had any effect on bcl-2 levels: $\mathrm{Vp}-16$ treatment alone decreased bcl-2 levels by three-fold compared with control cells (Figure 6A); on the contrary, the levels of bcl-2 were three-fold and five-fold increased in cells co-treated with $\mathrm{Vp}-16$ and aspirin at 2 and $5 \mathrm{mM}$ compared with Vp-16 treated cells, respectively (Figure 6B). bcl-2 levels were increased by approximately 1.5 -fold and two-fold in $\mathrm{Vp}-16$ co-treated cells with NS 398 at 10 and $50 \mu \mathrm{M}$, respectively, compared with $\mathrm{Vp}-16$ treated cells (Figure 6B). The above all data indicated that the effects of aspirin and NS-398 treatments on bcl-2 protein family expression persisted in co-treatment and again were consistent with the effects of aspirin and anticancer drugs administrations at different doses on apoptosis of Caco-2 cells.
Table I Cell cycle distribution (per cent) of control and Aspirin- or NS 398-treated Caco-2 cells

\begin{tabular}{lccc}
\hline Treatment & G0-GI & S & G2-M \\
\hline Control & 58 & 33 & 9 \\
Asp 2 mM & 51 & 46 & 3 \\
Asp 5 mM & 50 & 48 & 2 \\
NS 398 10 $\mu \mathrm{M}$ & 62 & 29 & 9 \\
NS 398 50 $\mu \mathrm{M}$ & 64 & 29 & 7 \\
\hline
\end{tabular}

DNA cell cycle analysis was performed by propidium iodide labelling as described in Material and Methods.

Table 2 Cell cycle distribution (per cent) of Caco-2 cells after anticancer drug treatments and anticancer drug plus aspirin or NS-398 co-treatments

\begin{tabular}{|c|c|c|c|}
\hline Treatment & G0-GI & $\mathbf{S}$ & G2-M \\
\hline Control & 58 & 33 & 9 \\
\hline$V_{p}-1617 \mu \mathrm{M}$ & 9 & 0 & 91 \\
\hline Asp $2 \mathrm{~mm}+\mathrm{Vp}-1617 \mu \mathrm{M}$ & 15 & 0 & 85 \\
\hline Asp $5 \mathrm{~mm}+\mathrm{V}_{\mathrm{p}}-1617 \mu \mathrm{M}$ & 37 & 0 & 63 \\
\hline NS $10 \mu \mathrm{M}+V_{\mathrm{p}}-1617 \mu \mathrm{M}$ & 8 & 0 & 92 \\
\hline NS $50 \mu \mathrm{M}+V_{\mathrm{p}}-1617 \mu \mathrm{M}$ & 15 & 0 & 85 \\
\hline CРT $1110 \mu \mathrm{M}$ & 22 & 70 & 8 \\
\hline Asp $2 \mathrm{~mm}+\mathrm{CPT} \| \mathrm{I} 10 \mu \mathrm{M}$ & 22 & 78 & 0 \\
\hline Asp $5 \mathrm{mM}+\mathrm{CPT}$ । $110 \mu \mathrm{M}$ & 35 & 65 & 0 \\
\hline NS $10 \mu \mathrm{M}+\mathrm{CPT} 1110 \mu \mathrm{M}$ & 15 & 85 & 0 \\
\hline NS $50 \mu \mathrm{M}+$ CPT $1110 \mu \mathrm{M}$ & 32 & 68 & 0 \\
\hline
\end{tabular}

DNA cell cycle analysis was performed by propidium iodide labelling as described in Materials and Methods.

\section{DISCUSSION}

Mounting evidence suggest that aspirin and other NSAID are able to interfere with mitogenic signalling causing arrest of cells in the G0/G1 phase of the cell cycle and, depending on the doses and the drug, to induce apoptosis as conventional cytotoxic drugs (Lu et al, 1995; Shiff et al, 1995, 1996; Piazza et al, 1995; Arber et al, 1997). For these properties NSAIDs have been sporadically employed in clinical cancer therapy; more frequently, they are utilised as analgesic, occasionally concurrently chemotherapy administration without a profound knowledge of the potential interaction with anticancer drugs and their efficacy. To date, very little information has been reported on this subject; a paper describes the first extensive screen of commercially available NSAIDs with anticancer drugs and discusses the potential clinical benefits of such combinations (Duffy et al, 1998). More recently, several studies have investigated the possibility of Cox-2 selective inhibitor-mediated enhancement of chemotherapeutic drug toxicity (Soriano et al, 1999; Hida et $a l, 2000)$. There are not reports comparing the effects of Cox-2 selective inhibition on responsiveness of colon cancer cells to chemotherapy with that obtained with aspirin, the most frequently used medicinal drug also for its anti-aggregating properties and in the clinical treatment of inflammatory diseases. In particular, the use of aspirin for analgesia and antipyresis $(650 \mathrm{mg}$ of oral administration, six times more on average than the anti-platelet dose) results in peak plasma concentration of $25 \mu \mathrm{g} \mathrm{ml}$ (which corresponds approximately to $0.15 \mathrm{~mm}$ ). On the other hand, the high dose of aspirin required for the treatment of arthritis (4-6 g of oral administration) determines aspirin plasma level up to $300 \mu \mathrm{g} \mathrm{ml}$, which corresponds to $2 \mathrm{mM}$ (Insel, 2001). The main purpose of this study is to evaluate if combined treatment in vitro would produce interactive effects that could be relevant in the clinical use. We have previously demonstrated that aspirin and NS-398 treatments are both associated with the inhibition of proliferation and induction of apoptosis of Caco-2 cells (Ricchi et al, 1997; Di 

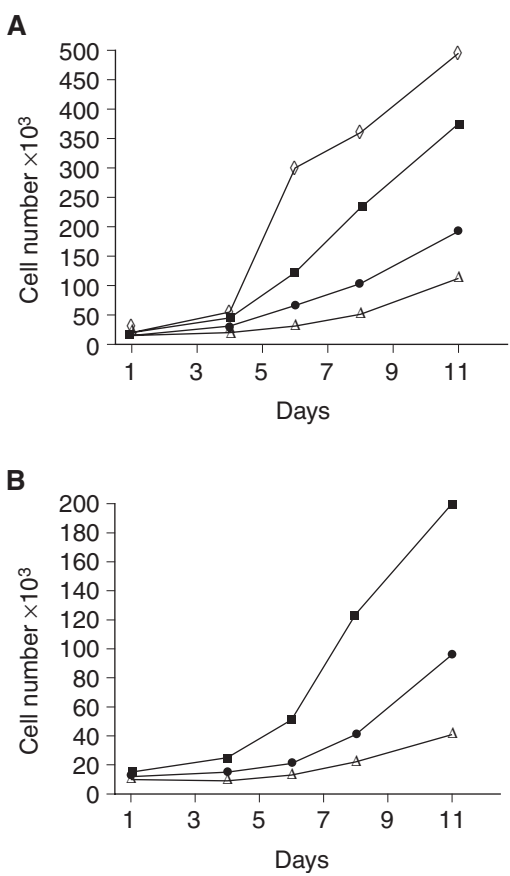

Figure 5 Effect of 2 and $5 \mathrm{mM}$ aspirin and VP-16 at $8.5 \mu \mathrm{M}(\mathbf{A})$ or $17 \mu \mathrm{M}$ (B) co-treatments on plating efficiency of Caco-2 cells. After each treatment, 15000 cells were seeded in triplicate in 24 multiwell dishes and counted at day I, 4, 6, 8 and II. All data points represent the mean of triplicate experiments.

Popolo et al, 2000). Numerous studies suggest that any interference with mitogenic signalling and cell cycle cause a modification in the responsiveness to conventional cytotoxic drugs. In the present study, we investigate whether aspirin and NS-398 interference with cell proliferation has any effect on Caco- 2 cells responsiveness to the topoisomerase poisons irinotecan and etoposide, anticancer agents that specifically require DNA synthesis to exert their toxicity.

The data reported herein demonstrate that aspirin and NS-398 act as anticancer agents in Caco-2 colon cancer cells with cytostatic properties and with different ability to induce apoptosis at high dosages. Also, we show that they differently modify anticancer responsiveness to chemotherapy of Caco- 2 cells. We have evaluated this effect mainly towards the induction of apoptosis. In fact, there is emerging evidence that resistance to antitumour treatments relies on reduced sensitivity to apoptosis induction (Fisher, 1994; Nagata, 1997); in this regard, our results demonstrate that aspirin treatment is able to counteract the proapoptotic effect of anticancer drugs in vitro.

Aspirin co-treatment produces, at all concentrations investigated, a reduction of anticancer drug-induced apoptosis in Caco2 cells and, at $5 \mathrm{mM}$, a reduction of S/G2 phase cell cycle accumulation. We hypothesise that the effects of high doses of aspirin cotreatment on anticancer drug-induced toxicity could be mainly explained by the almost complete inhibition of DNA synthesis and G1 cell cycle arrest obtained at this dose of aspirin that have been shown also to alter cell cycle-related proteins (Law et al, 2000; Marra et al, 2000); the reduced ability of such anticancer drugs to induce apoptosis in quiescent cells have been already observed (Nitiss and Wang, 1996: Lin et al, 1998). Furthermore, it is a common observation that agents able to interfere with cell cycle usually prevent the action of drugs active in the next phase of cell cycle (Lin et al, 1998).

Moreover, we clearly demonstrate by PI- and annexin V-staining that the reduced levels of apoptosis obtained in aspirin co-treat- ments are associated with an increase in cell viability of Caco-2 cells; this effect is also evident by the analysis of plating efficiency in aspirin-Vp 16 co-treated cells; thus, these data indicate that aspirin co-treatment interferes not only with apoptotic death but also with overall toxicity induced by these anticancer drugs. In this regard, aspirin and its metabolite sodium salicylate have been found to be protective against neurotoxicity elicited by the excitatory amino acid glutamate in rat primary neuronal cultures (Grilli et al, 1996); thus, our data may represent a further evidence of aspirin cytoprotective property against a cellular damage.

In addition, PI- and annexin V-staining assay indicated that the cytoptotective effect of aspirin co-treatment is present not only in Caco- 2 cells but also in the Cox-2 negative, Cox-1 positive Sw 480 colon cancer cell line. These data may suggest that aspirin interferes with topoisomerase poison-induced toxicity through a Cox-independent mechanism.

On the other hand, our data show that NS-398 co-treatment may alternatively reduce or increase anticancer drug induced apopotosis, depending on the concentration. These effects are less powerful compared with those observed in the presence of aspirin. NS-398 at $1 \mu \mathrm{m}$ concentration completely inhibits the biosynthesis of prostaglandin $\mathrm{E}_{2}$ in Caco-2 cells (Acquaviva et al, unpublished data) without affecting anticancer drug responsiveness; NS 398, at $10 \mu \mathrm{m}$ concentration, causes minimal enhancement of anticancer drug-induced apoptosis without modifying cell cycle parameters. On the contrary, our data show that NS-398, at dose of $50 \mu \mathrm{M}$, is cytoprotective and counteracts anticancer drugsinduced cell cycle perturbation. Based on these findings, we postulated that the described effects of increasing dose of NS-398, as in the case of aspirin, might be dependent on regulation of cell cycle regulatory protein (Hung et al, 2000) and not related on the inhibition of Cox-2 activity; these data could also reinforce the hypothesis of the concurrent presence of Cox-2-dependent and independent mechanisms of action in the antiproliferative effect of individual selective Cox-2 inhibitors (Grösch et al, 2001; Smith et al, 2000).

Several reports suggest that the regulation of the cell response to chemotherapeutic drugs may also involve a dynamic interplay among the bcl-2 protein family members (Yang and Korsmeyer, 1996), on which novel treatment approaches have focused to overcame drug resistance (Strobel et al, 1998a,b; Kobayashi et al, 1998). In this regard, searching for an alternative and/or complementary mechanism to cell cycle block, we have evaluated the effect of aspirin and NS-398 treatment on these proteins. Levels of bax, bad and bclx-xl are not significantly affected by these treatments. On the contrary, we demonstrate that aspirin treatment is associated with a dose dependent increase of bcl-2, that play a pivotal role extending cell survival through the inhibition of apoptosis induced by various stimuli, including chemotherapeutic drugs (glucocorticoids, alkylating agents, topoisomerase II inhibitors). The increase in bcl-2 levels is more evident at dose of $5 \mathrm{~mm}$ aspirin, is detectable in co-treatment and may be responsible for the induction of a survival signal in Caco-2 cells and for the increase in viability observed in co-treatments. It has been recently demonstrated that bcl-2 expression is increased at G1 phase of cell cycle (Gao and Dou, 2000). Because we have demonstrated that $5 \mathrm{~mm}$ aspirin treatment in the presence of $\mathrm{Vp}-16$ and CPT 11 increases the percentage of cells at G1 phase, we postulated that the observed increase of bcl-2 expression might be dependent on a G1 phase arrest. However, $5 \mathrm{~mm}$ aspirin treatment determines a modest increase in the levels of apoptosis also in the presence of increased bcl-2 expression; further studies are needed to clarify this phenomenon. Moreover, the levels of antiapoptotic bcl-2 protein are decreased by NS-398 treatment at $10 \mu \mathrm{M}$ and to a lesser extent at $50 \mu \mathrm{M}$. These modifications persist after anticancer drug treatment and again strictly correlate with data on apoptosis in co-treatments; these findings confirm previous reports showing that bcl-2 protein levels can affect apoptosis induced by etoposide (Kamesaki et al, 
A
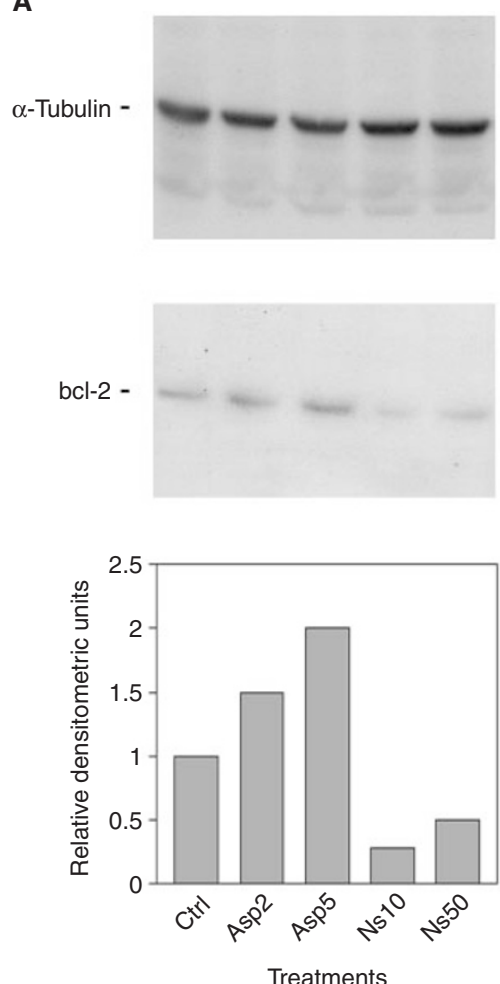

B
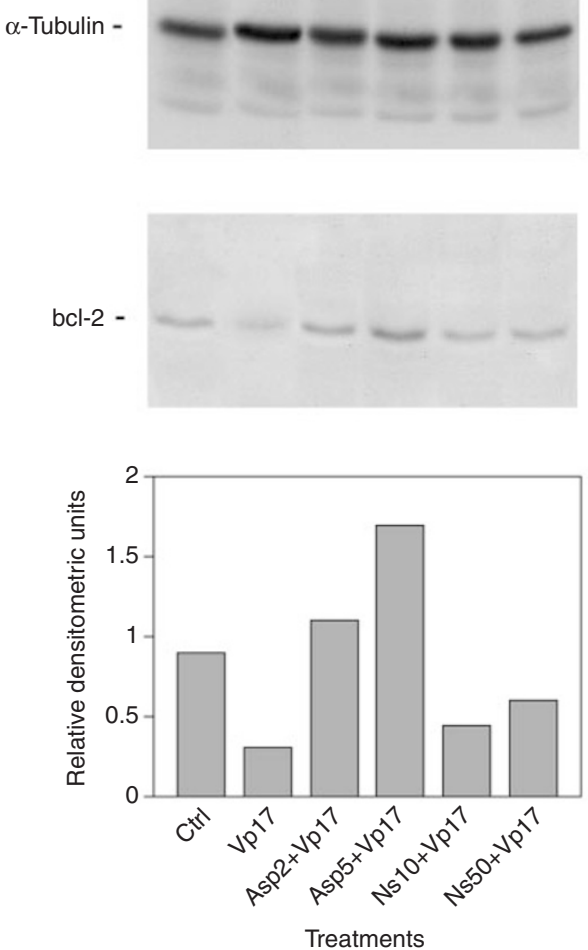

Figure 6 (A) Effect of single agent treatment on $\alpha$-tubulin and bcl-2 expression in Caco-2 cells. Upper panel: Western immunoblot analysis of protein lysates from control cells (lane I), from cell treated with aspirin for $72 \mathrm{~h}$ at $2 \mathrm{mM}$ (lane 2) and $5 \mathrm{mM}$ concentrations (lane 3), from cell treated with NS-398 for $72 \mathrm{~h}$ at $10 \mu \mathrm{M}$ (lane 4) and $50 \mu \mathrm{M}$ (lane 5). Lower panel: densitometric analysis of the autoradiograph shown. A representative experiment of three separate ones is shown. (B) Effect of aspirin and NS-398 co-treatments on $\alpha$-tubulin and bcl-2 expression in Caco-2 cells. Upper panel: Western immunoblot analysis of protein lysates from untreated (lane I), from cell treated with VP-16 for $48 \mathrm{~h}$ at $17 \mu \mathrm{M}$ (lane 2), from cell co-treated with $17 \mu \mathrm{M}$ VP-16 and $2 \mathrm{mM}$ aspirin (lane 3), from cells co-treated with $17 \mu \mathrm{M}$ VP- 16 and $5 \mathrm{mM}$ aspirin (lane 4), from cells co-treated with $17 \mu \mathrm{M}$ VP-I6 and I0 $\mu \mathrm{M}$ NS-398 (lane 5), from cells co-treated with $17 \mu \mathrm{M}$ VP-16 and $50 \mu \mathrm{M}$ NS-398 (lane 6). Lower panel: densitometric analysis of the autoradiograph shown. A representative experiment of three separate ones is shown.

1993; Dole et al, 1994). Further studies are needed to investigate if the effects we observed in vitro are specific for a cancer cell type and for phase specific anticancer agents or are a more general phenomenon reproducible in vivo also for the aspirin metabolite salicylate. In fact, preliminary reports indicate that this aspirin metabolite also affects cell growth (Elder et al, 1996).

Finally our data prompt to accurately investigate all the possible interference between aspirin or others NSAID and anticancer drugs and other genotoxic damages in vivo and in vitro. Our finding may have important implications for treatment schedules involving both cytotoxic agents and aspirin in malignancies; they could suggest to absolutely avoid co-treatment of aspirin and anticancer drugs. On the other hand, they could also provide a rationale for novel strategies of enhancement of chemotherapy activity: in fact, Cox-2 selective inhibition could be a feasible and not toxic tool to increase chemotherapy effectiveness.

\section{REFERENCES}

Arber N, Han EK, Sgambato A, Piazza GA, Delohery TM, Begemann M, Weghorst CM, Kim NH, Pamukcu R, Ahnen DJ, Reed JC, Weinstein IB, Holt PR (1997) A K-ras oncogene increases resistance to sulindac-induced apoptosis in rat enterocytes. Gastroenterology 113: $1892-1900$

Chan TA, Morin PJ, Vogelstein B, Kinzler KW (1998) Mechanisms underlying nonsteroidal antiinflammatory drug-mediated apoptosis. Proc Natl Acad Sci (USA) 95: 681-686

\section{ACKNOWLEDGEMENTS}

We thank M Berardone for the artwork and R Cerillo for technical support. Data from this work were presented in part at the Annual Meeting of the American Association for Cancer Research April 15, 2000 San Francisco, CA, and the author was recipient of a 'Pezcoller Foundation' Award. This work was supported by grants from Associazione Italiana per la Ricerca sul Cancro (AIRC) and Ministero dell'Università e della Ricerca Scientifica e Tecnologica (MURST). Dr A Apicella and Dr T Di Matola were recipients of a fellowship from Fondazione Italiana per la Ricerca sul Cancro (FIRC).

Chen G, Shu J, Stacey DW (1997) Oncogenic transformation potentiates apoptosis, S-phase arrest and stress-kinase activation by etoposide. Oncogene 15: $1643-1651$

Ciardiello F, Damiano V, Bianco R, Bianco C, Fontanini G, De Laurentiis M, De Placido S, Mendelsohn J, Bianco AR, Tortora G (1996) Antitumor activity of combined blockade of Epidermal Growth Factor receptor and protein kinase A. J Natl Cancer Inst 88: 1770-1776 
De Luca A, Selvam MP, Sandomenico C, Pepe S, Bianco AR, Ciardiello F, Salomon DS, Normanno N (1997) Anti-sense oligonucleotides directed against EGF-related growth factor enhance anti-proliferative effect of conventional anti-tumor drugs in human colon-cancer cells. Int J Cancer 73: $277-282$

Di Popolo A, Memoli A, Apicella A, Tuccillo C, di Palma A, Ricchi P, Acquaviva AM, Zarrilli R (2000) IGF-II/IGF receptor pathway up-regulates COX-2 mRNA expression and PGE2 synthesis in Caco-2 human colon carcinoma cells. Oncogene 19: 5517-5524

Dole M, Nunez G, Merchant AK, Maybaum J, Rode CK, Bloch CA, Castle VP (1994) Bcl-2 inhibits chemotherapy-induced apoptosis in neuroblastoma. Cancer Res 54: 3253 - 3259

Donaldson KL, Goolsby GL, Wahl AF (1994) Citotoxity of the anticancer agents cisplatin and taxol during cell proliferation and cell cycle. Int $J$ Cancer 57: 847 - 855

Downes CS, Clarke DJ, Mullinger AM, Gimenez-Abian JF, Creighton AM, Johnson RT (1994) A topoisomerase II-dependent G2 cycle checkpoint in mammalian cells. Nature 372: $467-440$

Duffy CP, Elliott CJ, O'Connor RA, Heenan MM, Coyle S, Cleary IM Kavanagh K, Verhaegen S, O'Loughlin CM, NicAmhlaoibh R, Clynes M (1998) Enhancement of chemotherapeutic drug toxicity to human tumour cells in vitro by a subset of non-steroidal anti-inflammatory drugs (NSAIDs). Eur J Cancer 34: $1250-1259$

Elder DJ, HagueA, Hicks DJ, Paraskeva C (1996) Differential growth inhibition by the aspirin metabolite salicylate in human colorectal tumor cel lines: enhanced apoptosis in carcinoma and in vitro-transformed adenoma relative to adenoma cell lines. Cancer Res 56: 2273-2276

Fearnhead HO, Lin M, Snowden RT, Ormerod G, Cohen GM (1994) Dexamethasone and etoposide induce apoptosis in rat thymocytes from different phases of the cell cycle. Biochem Pharmacol 48: 1073-1079

Fisher DE (1994) Apoptosis in cancer therapy: crossing the threshold. Cell 78: $539-542$

Gao G, Dou QP (2000) G(1) phase-dependent expression of bcl-2 mRNA and protein correlates with chemoresistance of human cancer cells. Mol Phar macol 58: 1001 - 1010

Goldwasser F, Bae I, Valenti M, Torres K, Pommier Y (1995) Topoisomerase I-related parameters and camptothecin activity in the colon carcinoma cell lines from the National Cancer Institute Anticancer Screen. Cancer Res 55: $2116-2121$

Grilli M, Pizzi M, Memo M, Spano PF (1996) Neuroprotection by aspirin and sodium salicylate through blockade of NF-kB activation. Science 274 $1383-1385$

Grösch S, Tegeder I, Niederberger E, Bräutigam L, Geisslinger G (2001) COX2 independent induction of cell cycle arrest and apoptosis in colon cancer cells by the selective COX-2 inhibitor celecoxib. FASEB J 15: 2742-2744

Han JW, Dionne CA, Kedersha NL, Goldmacher VS (1997) p53 status affects the rate of the onset but not the overall extent of doxorubicin-induced cell death in rat-1 fibroblasts constitutively expressing c-Myc. Cancer Res 57: $176-182$

Hida T, Kozaky K, Muramatsu H, Masuda A, Shimizu S, Mitsudomi T, Sugiura T, Ogawa M, Takahashi T (2000) Cyclooxigenase-2 inhibitor induce apoptosis and enhances cytotoxicity of variuos anticancer agents in Non-small cell lung cancer lines. Clin Cancer Res 6: 2006-2011

Hung WC, Chang HC, Pan MR, Lee TH, Chuang LY (2000) Induction of $\mathrm{p} 27^{\mathrm{KIP} 1}$ as a mechanism underlying NS398-induced growth inhibition in human lung cancer cells. Mol Pharmacol 58: 1398-1403

Insel PA (2001) The pharmacological basis of therapeutics. In Goodman and Gilman's JG Hardman PB, Molinoff RW, Rudden Goodman Gilman A. (eds) pp 687-731. McGraw-Hill: New York

Kamesaki S, Kamesaki H, Jorgensen TJ, Tanizawa A, Pommier Y, Cossman J (1993) Bcl-2 protein inhibits etoposide-induced apoptosis through its effect on events subsequent to topoisomerase II-induced DNA strand breaks and their repair. Cancer Res 53: 4251-4256

Korsmeyer SJ (1999) Bcl-2 gene family and the regulation of programmed cell death. Cancer Res 59: $1693-1700$

Kobayashi T, Ruan S, Clodi K, Kliche KO, Shiku H, Andreeff M, Zhang W (1998) Overexpression of bax gene sensitizes K562 erythroleukemia cells to apoptosis induced by selective chemotherapeutic agents. Oncogene 16: $1587-1591$

Law BK, Waltner-Law ME, Entingh AJ, Chytil A, Aakre ME, Norgaard P, Moses HL (2000) Salicylate-induced growth arrest is associated with inhibition of p70s6k and down-regulation of c-myc, cyclin D1, cyclin A, and proliferating cell nuclear antigen. J Biol Chem 275: 38261-38267
Li H, Schut HA, Conran P, Kramer PM, Lubet RA, Steele VE, Hawk EE, Kelloff GJ, Pereira MA (1999) Prevention by aspirin and its combination with alpha-difluoromethylornithine of azoxymethane-induced tumors, aberrant crypt foci and prostaglandin E2 levels in rat colon. Carcinogenesis 20: $425-$ 430

Lin CK, Nguyen TT, Morgan TL, Mei RL, Kaptein JS, Kalunta CI, Yen CF, Park E, Zou HY, Lad PM (1998) Apoptosis may be either suppressed or enhanced with strategic combination of antineoplastic drugs or antiIgM. Exp Cell Res 10: 1-13

Lu X, Xie W, Reed D, Bradshaw WS, Simmons DL (1995) Nonsteroidal antiinflammatory drugs cause apoptosis and induce cyclooxygenases in chicken embryo fibroblasts. Proc Natl Acad Sci USA 92: 7961-7965

Lundholm K, Gelin J, Hyltander A, Lonnroth C, Sandstrom R, Svaninger G, Korner U, Gulich M, Karrefors I, Norli B, HafstromLO, Kewenter J, Olbe L, Lundell L (1994) Anti-inflammatory treatment may prolong survival in undernourished patients with metastatic solid tumors. Cancer Res 54: $5602-5606$

Marra DE, Simoncini T, Liao JK (2000) Inhibition of vascular smooth muscle cell proliferation by sodium salicylate mediated by up-regulation of p21(Waf1) and p27(Kip1). Circulation 102: 2124-2130

Mcdonald AC, Brown R (1998) Induction of p53-dependent and p53-independent cellular responses by topoisomerase 1 inhibitors. $\mathrm{Br} \mathrm{J}$ Cancer 78: $745-751$

Nagata S (1997) Apoptosis by death factor. Cell 88: $355-365$

Nicoletti I, Migliorati G, Pagliacci MC, Grignani F, Riccardi C (1991) A rapid and simple method for measuring thymocyte apoptosis by propidium iodide staining and flow citometry. J Immunol Methods 139: 271-279

Nitiss JL, Beck WT (1996) Antitopoisomerase drug action and resistance. Eur J Cancer 32A: $958-986$

Nitiss JL, Wang JC (1996) Mechanisms of cell killing by drugs that trap covalent complexes between DNA topoisomerases and DNA. Mol Pharmacol 50: $1095-1102$

Piazza GA, Rahm AL, Krutzsch M, Sperl G, Paranka NS, Gross PH, Sperl GJ, Pamukcu R, Ahnen DJ (1995) Antineoplastic drugs sulindac sulfide and sulfone inhibit cell growth by inducing apoptosis. Cancer Res 55: $3110-$ 3116

Ricchi P, Pignata S, Di Popolo A, Memoli AM, Apicella A, Zarrilli R, Acquaviva AM (1997) Effect of aspirin treatment on cell proliferation and differentiation of colon adenocarcinoma Caco-2 cells. Int J Cancer 73: $880-884$

Rougier P, Van Cutsem E, Bajetta E, Niederle N, Possinger K, Labianca R, Navarro M, Morant R, Bleiberg H, Wils J, Awad L, Herait P, Jacques C (1998) Randomised trial of irinotecan versus fluorouracil by continuous infusion after fluorouracil failure in patients with metastatic colorectal cancer. Lancet 352: $1407-1412$

Shao RG, Cao CX, Shimizu T, O’Connor PM, Kohn KW, Pommier Y (1997) Abrogation of an S-phase checkpoint and potentiation of camptothecin cytotoxicity by 7-hydroxystauroporine (UCN-01) in human cancer cell lines, possibly influenced by p53 function. Cancer Res 57: 4029-4035

Sheng H, Shao J, Morrow JD, Beauchamp RD, DuBois RN (1998) Modulation of apoptosis and Bcl-2 expression by prostaglandin E2 in human colon cancer cells. Cancer Res 58: $362-366$

Shiff SJ, Qiao L, Tsai LL, Rigas B (1995) Sulindac sulfide, an aspirin-like compound, inhibits proliferation, causes cell cycle quiescence, and induces apoptosis in HT-29 colon adenocarcinoma cells. J Clin Invest 96: 491 - 503

Shiff SJ, Koutsos MI, Qiao L, Rigas B (1996) Nonsteroidal anti-inflammatory drugs inhibit the proliferation of colon adenocarcinoma cells: effects on cell cycle and apoptosis. Exp Cell Res 222: 179-188

Sinicrope FA, Pazdur R, Levin B (1996) Phase I trial of sulindac plus 5-fluorouracil and levamisole: potential adjuvant therapy for colon carcinoma. Clin Cancer Res 2: 37-41

Smith ML, Hawcroft G, Hull MA (2000) The effect of non-steirodal antiinflammatory drugs on human colorectal cancer cell: evidence of different mechanisms of action. Eur J Cancer 36: 664-674

Soriano AF, Helfrich B, Chan DC, Heasley LE, Bunn Jr PA, Chou TC (1999) Synergistic effects of new chemopreventive agents and conventional cytotoxic agents against human lung cancer cell lines. Cancer Res 59: 6178 6184

Strobel T, Kraeft SK, Chen LB, Cannistra SA (1998a) BAX expression is associated with enhanced intracellular accumulation of paclitaxel: a novel role for BAX during chemotherapy-induced cell death. Cancer Res 58: 47764781 
Strobel T, Tai YT, Korsemeyer SJ, Cannistra SA (1998b) Bad partly reverses paclitaxel resistance in human ovarian cancer cells. Oncogene 17: $2419-$ 2427

Torrance CJ, Jackson PE, Montgomery E, Kinzler KW, Vogelstein B, Wissner A, Nunes M, Frost P, Discafani CM (2000) Combinatorial chemoprevention of intestinal neoplasia. Nat Med 6: 1024-1028

Tortora G, di Isernia G, Sandomenico C, Bianco R, Pomatico G, Pepe S, Bianco AR, Ciardiello F (1997) Synergistic inhibition of growth and induction of apoptosis by 8-chloro-cAMP and paclitaxel or cisplatin in human cancer cell. Cancer Res 57: $107-111$

Vidair CA, Chen CH, Ling CC, Dewey WC (1996) Apoptosis induced by Xirradiation of rec-myc cells is post-mitotic and not predicted by the time after irradiation or behaviour of sister cells. Cancer Res 56: 4116-4118
Yang E, Zha J, Jockel J, Boise LH, Thompson CB, Korsmeyer SJ (1995) Bad, a heterodimeric partner for Bcl-XL and Bcl-2, displaces Bax and promotes cell death. Cell 80: 285-291

Yang E, Korsmeyer SJ (1996) Molecular thanatopsis: a discourse on the BCL2 family. Blood 88: $386-401$

Zarrilli R, Pignata S, Romano M, Gravina A, Casola S, Bruni CB, Acquaviva AM (1994) Expression of insulin-like growth factor (IGF)-II and IGF-I receptor during proliferation and differentiation of Caco-2 human colon carcinoma cells. Cell Growth Differ 5: $1085-1091$

Zarrilli R, Romano M, Pignata S, Casola S, Bruni CB, Acquaviva AM (1996) Constitutive insulin-like growth factor-II expression interferes with the enterocyte-like differentiation of Caco-2 cells. J Biol Chem 271: 8108-8114 